\title{
Feeding Habits and Density Patterns of Greenland Cod, Gadus ogac (Richardson 1836), at West Greenland Compared to Those of the Coexisting Atlantic Cod, Gadus morhua L.
}

\author{
J. Rasmus Nielsen ${ }^{1}$ \\ Danish Institute for Fisheries Research, Department of Fish Biology \\ North Sea Centre, DK-9850 Hirtshals, Denmark \\ and \\ Michael Andersen \\ Danish Fishermens Association, H. C. Andersens Boulevard 37 \\ DK-1553 Copenhagen V, Denmark.
}

\begin{abstract}
The diet of Greenland cod (Gadus ogac) was found to be very similar to that of the coexisting Atlantic cod (Gadus morhua) based on stomach analyses of length groups larger than $30 \mathrm{~cm}$ sampled by longline in West Greenland waters. Estimation of relative frequency and relative weight of each food group in relation to predator length as well as mean partial stomach fullness index (PFI) and mean total fullness index (TFI) were performed. Mean TFI was found to be higher in the inshore areas compared to that of the coastal areas for both species. However, greatest variation in TFI was also observed in the inshore areas for both species. Gadus ogac feed on a broad variety of prey species, although fish (especially capelin, Mallotus villosus) and larger invertebrate prey groups (especially larger Malacostraca) were found to be the main diet in the autumn period. The importance of fish in the diet increased with length, in particular fish species other than capelin. Among the invertebrates the shrimps and crabs (large Malacostraca) were the most important food groups. Shrimps were most important prey for small predators $(<50 \mathrm{~cm})$ of both species. However, while fish became dominant prey for larger G. ogac, large Crustacea (crabs, Brachyura) were primary food for larger G. morhua. In general, small (planktonic) Crustacea were not important in the diet of any of the settled size groups investigated of both species. The stomach content analyses of the two species were made in combination with comparative studies of their occurrence at West Greenland to investigate the degree of coexistence and overlap in distribution, in order to get an impression of potential interspecific competition for food and space or of interspecific predation. Comparative ANOVA analyses of $G$. ogac and G. morhua density patterns based on catch rate data from the same longline research fishery (1987-89), showed statistically significant coexistence and overlap in their distribution. Both species occurred with highest densities in the central part of West Greenland, and with highest overlap in occurrence in coastal and shallow waters. The broad overlap in distribution and diet in the autumn in West Greenland waters indicate the potential for interspecific competition for food and space.
\end{abstract}

Keywords: Atlantic cod, borders of distribution, coexistence, distribution, density patterns, feeding ecology, Gadus morhua, Gadus ogac, Greenland cod, interspecific competition, West Greenland.

\section{Introduction}

Since the early-1970s Greenland cod (Gadus ogac) has been commercially exploited at West Greenland with maximum landings during periods when Atlantic cod (Gadus morhua) landings were decreasing in the area (Nielsen, MS 1992a, MS 1992b; ICES, 2000; Buch et al., 1994). The West Greenland (bank) G. morhua stock has not produced any good year-classes since the late-1960s. All important year-classes since then have

\footnotetext{
1 Author to whom all correspondence should be addressed. Email: rn@dfu.min.dk
} 
been of Icelandic origin: (ICES, 2000; Buch et al., 1994). The most recent of these were the 1984 and 1985 year-classes that sustained the cod fishery during 198890. The recent (since 1991) collapse of the G. morhua fishery in West Greenland waters as a consequence of the low recruitment from the 1986-97 year-classes and no strong contributions from G. morhua spawned at Iceland (ICES, 2000; Buch et al., 1994), has created a demand for alternative fishery resources and resulted in growing interest in increased exploitation of G. ogac.

The Greenland Fisheries Research Institute (now Greenland Institute of Natural Resources) started two research projects in 1988 on population dynamics and feeding biology of $G$. ogac in order to increase the knowledge of its biology in relation to potential increased exploitation of the species (Nielsen, MS 1992a, MS 1992b; Andersen, MS 1991; Nielsen and Morin, 1993). This paper describes the occurrence and overlap in distribution of G. ogac and G. morhua as well as the feeding habits of the two species at West Greenland in order to examine potential interspecific competition for e.g. food and space between the two species or of interspecific predation. The possible impacts of interspecific competition is relevant from a resource management point of view, because of the relative high commercial importance of the two cod species in West Greenland (Nielsen, MS 1992a, MS 1992b; Nielsen and Morin, 1993; ICES, 2000; Buch et al., 1994).

Possible overlap in species specific intermediary scale distribution and similarity in density patterns of adult G. ogac and G. morhua of mainly the same size groups, compared with possible overlap in diet (based on the comparative feeding analyses) of the same size groups may be an indication of potential competition in inshore and coastal waters of West Greenland. We know that G. ogac is mainly distributed in inshore and coastal areas (Andersen et al., 1994; Nielsen, MS 1992a), and these two cod species seem to coexist in the southern part of the G. ogac distribution area at West Greenland which extends southwards to NAFO Div. 1E (Jensen, 1948; Hansen, 1949; Nielsen, MS 1992a; Nielsen and Morin, 1993). Furthermore, both species are characterized as being omnivorous opportunists (Hansen, 1949; Nielsen, MS 1992a). In context of the above, the objectives of the analyses in the present study have been to test the hypotheses that:

- the feeding patterns and diet of the two cod species are overlapping and similar by size, giving the potential for interspecific competition (h:1)
- the distribution and density patterns of the two species overlap, i.e. there exists a statistically significant high degree of coexistence of the two species in some areas of West Greenland waters, giving the potential for interspecific competition $(\mathrm{h}: 2)$

- the highest degree of coexistence, i.e. highest overlapping densities, between the two species are in the central part of West Greenland taking into account the northern distribution limit of the more boreal G. morhua (Jensen, 1948; Hansen, 1949) and the southern distribution limit of the more arctic G. ogac in West Greenland (Jensen, 1948; Nielsen and Morin, 1993) (h:3)

- the two species are in general potential interspecific competitors in West Greenland waters $(h: 4)$

\section{Materials and Methods}

The analyses were based on catch rate data (covering Northwest Atlantic Fisheries Organization (NAFO) Divisions 1B, 1C, 1D and 1E; 1987-89 period; Fig. 1 and Appendix Table 1) and stomach content data (covering Div. 1D; 1989; Fig. 2 and Table 1) for both species concurrently sampled in the same longline research fishery in inshore, coastal and offshore areas of West Greenland (Fig. 1-2).

Data and sampling stratification and procedures of analyses for stomach content data

Stomach sampling. In November 1989, 334 stomachs from $G$. ogac and 89 stomachs from G. morhua were concurrently sampled from inshore (fjord) and coastal longline catches at 17 stations located in the Nuuk/Godthåb area of West Greenland (Div. 1D; Fig. 2, Table 1). During sampling, the individuals used for stomach content analyses were selected to cover all length groups from a representative part of the total catch of both species (Table 2). The sampling at sea included measurements of total length (to $\mathrm{cm}$ below) and total weight (to nearest $10 \mathrm{~g}$ ) for each individual G. ogac and G. morhua. The samplings from selected individuals, as well as extraction and weighing of stomachs and weight measurements were performed just after the catches were taken on board, and the stomachs were preserved on board by freezing $\left(-18^{\circ} \mathrm{C}\right)$ immediately thereafter. During extraction of stomachs, before incision near the oesophagus, all stomach content was pressed backwards into the stomach lumen. This was followed by the incision just before the pyloric sphincter. To avoid analysing fish 


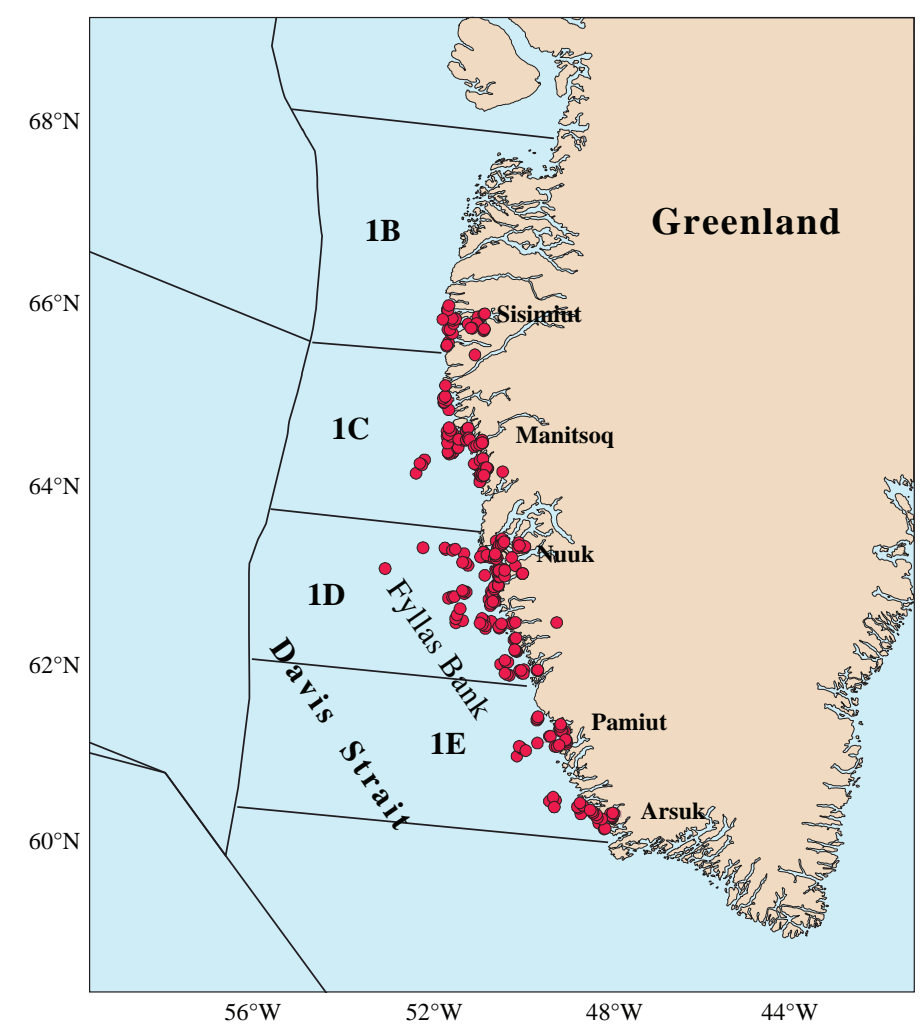

Fig. 1. The survey area and overall distribution of longline sample locations at West Greenland in autumn during the period 198789 by NAFO Division (1C, 1D, 1E, 1F). A total of 308 stations were sampled in this period. Stomach sampling of both Gadus morhua and Gadus ogac was performed at 17 stations in NAFO Division 1D in 1989.

that had regurgitated, individuals with the following characteristics were not included: a) the stomach was evert and positioned in the mouth cavity; b) the stomach was large, flaccid and empty; c) there was food remains in the gill rays.

Laboratory analyses of stomach contents. Each stomach contained in a plastic bag was thawed in a water bath and then weighed with a precision of $0.1 \mathrm{~g}$. Each stomach was then cut open, emptied and scraped clear of mucous before the empty stomach wet weight was determined (same precision). The stomach contents were sorted and identified to species or to the nearest taxonomic level possible (Appendix Table 2). The contents were divided into prey groups and classified with identical degrees of digestion (DoD) in 6 levels (1 to 6) based on the scale of Bromley and Last (MS 1990) (Appendix Table 3). Capelin, which were recognized as bait because of hook marks were deleted from the analyses. Also capelin identified as mature (pre-spawning) individuals (from occurrence of eggs in females), which are unlikely to occur naturally in the autumn (sampling) period because capelin spawn in spring, and consequently must originate from frozen bait, were deleted from the analyses. This was also done for capelin with a DoD value of 1 because of a high likelihood of being bait. The number of prey items was estimated for each group and total group weight to nearest $0.1 \mathrm{~g}$ was recorded. To avoid bias of mucous in the weight estimates, each prey organism was cleansed of mucous and placed on the scales with a pair of tweezers.

Data analyses of stomach contents. In relation to the stomach content analyses the following parameters were estimated based on the method described by Lilly and Rice (MS 1983):

a) Relative frequency of occurrence is the number of predator stomachs with prey item, $j$, as percentage 


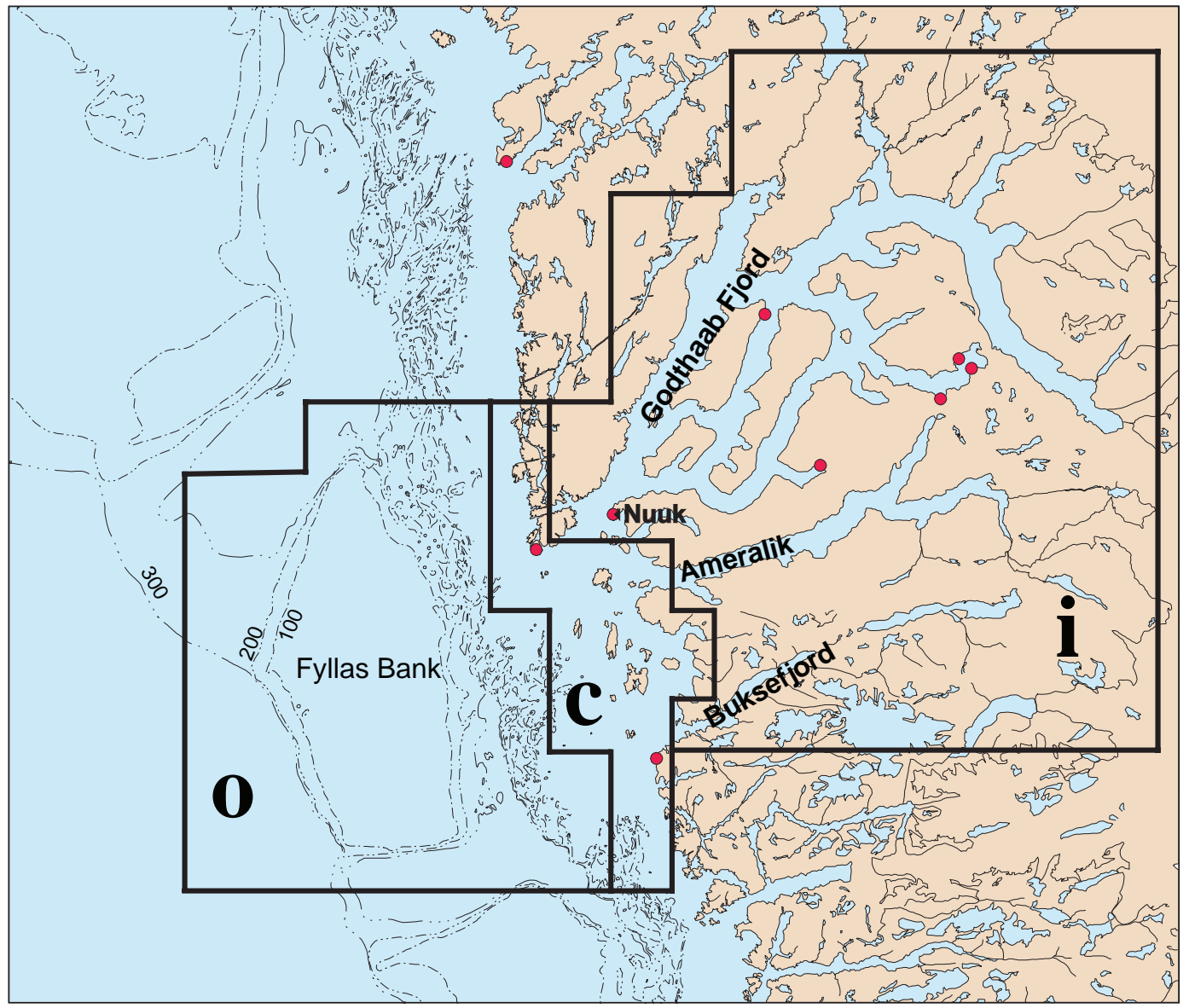

Fig. 2. The survey area in the Godthåb/Nuuk area, Div. 1D, West Greenland. The survey area is subdivided into offshore (o), coastal (c), and inshore (fjord) (i) areas. Depth strata contours (m) for the offshore localities are shown.

TABLE 1. Total number of analyzed stomachs by species, survey area and depth stratum. Also the relative numbers of empty stomachs are shown.

\begin{tabular}{|c|c|c|c|c|c|}
\hline Area & Depth stratum (m) & Gadus ogac & Percent empty & Gadus morhua & Percent empty \\
\hline & $0-100$ & 167 & $27.5 \%$ & 35 & \\
\hline \multirow[t]{3}{*}{ Coast } & $101-200$ & 37 & $18.9 \%$ & 9 & $3.8 \% *$ \\
\hline & $201-300$ & 46 & $30.4 \%$ & 9 & \\
\hline & $0-100$ & 55 & $54.5 \%$ & 34 & \\
\hline \multirow[t]{2}{*}{ Fjord } & $101-200$ & 26 & $11.5 \%$ & 2 & $5.6 \% *$ \\
\hline & $201-300$ & 3 & $0.0 \%$ & 0 & \\
\hline Total & $\ldots$ & 334 & $29.9 \%$ & 89 & $4.5 \%$ \\
\hline
\end{tabular}

* Percent empty is not divided by depth for Gadus morhua.

of the total number of predator stomachs. Occurrence of different prey taxa in a stomach were detected when at least one individual of a taxonomic group was present, and thus indicated how many predators had eaten a particular prey or prey group. 
TABLE 2. Numbers of analyzed stomachs for each species by fish length group with the relative number of empty stomachs designated.

\begin{tabular}{|c|c|c|c|c|}
\hline Length group $(\mathrm{cm})$ & Gadus ogac & Percent empty & Gadus morhua & Percent empty \\
\hline $30-34$ & 12 & $33.3 \%$ & 0 & \\
\hline $35-39$ & 68 & $30.9 \%$ & 6 & \\
\hline $40-44$ & 123 & $29.3 \%$ & 7 & $4.5 \%{ }^{*}$ \\
\hline $45-49$ & 93 & $37.6 \%$ & 12 & \\
\hline $50-54$ & 32 & $12.5 \%$ & 29 & \\
\hline$>55$ & 6 & $0.0 \%$ & 35 & \\
\hline Total & 334 & $29.9 \%$ & 89 & $4.5 \%$ \\
\hline
\end{tabular}

* Percent empty is not divided by length for Gadus morhua.

b) Relative weight $=$ total weight of prey item, $j$, as percentage of the weight of total stomach contents summed for all predators.

c) Mean partial fullness index (PFI):

$$
P F I=\frac{1}{n} \times \sum_{f=1}^{n} \frac{\text { weight of prey }_{j} \text { for fish }_{f}}{\left(\text { length } \text { of fish } \text { f }_{f}\right)^{3}} \times 10^{4}
$$

where $n$ is the number of predators (= fish), the weight is in $0.1 \mathrm{~g}$, and the length in $\mathrm{cm}$.

d) Mean total fullness index (TFI):

$T F I=\frac{1}{n} \times \sum_{f=1}^{n} \frac{\text { weight of stomach contents for fish } h_{f}}{\left.(\text { length of fish })_{f}\right)^{3}} \times 10^{4}$

where $n$ is the number of predators (= fish), the weight is in $0.1 \mathrm{~g}$, and the length in $\mathrm{cm}$.

If all stomach contents were identified, then $T F I$ will be equal to the sum of all PFI estimates. In the present study the total weight of the stomach content was estimated as the weight difference between the full and the empty stomach. However, since a certain part of the stomach content consisted of water, mucous and other material different from zoological prey items, TFI was estimated as net weight (= weight exclusive of water, mucous, etc.), which then was less than the sum of the PFI estimates. This method where the PFI were analyzed, rather than only the relative weights, has the advantage of taking into account possible heavy influence of frequent small organisms with small individual weights. Furthermore, the method compensates for high influence of infrequent prey organisms with heavy body weights. The method relates the weight of the stomach content to predator length, rather than to predator weight, to avoid the influence of stomach fullness as well as the condition (lengthweight relationship) of the fish in the estimates of $P F I$ and $T F I$.

To compare feeding activity between different areas and between predator length groups of the two cod species, TFI was calculated for stomach content data from individuals caught within each area (inshore (fjord) and coastal areas separately) and within $5 \mathrm{~cm}$ length groups. In the analysis of the prey by predator size, the PFI was calculated for different main prey groups sorted based on both the general importance of the prey and the prey size. Most stomachs from G. ogac and $G$. morhua were sampled from the coastal area. Comparative analyses of the food composition for each species caught in the coastal and inshore (fjord) area, respectively, examining for differences in relative weights and frequencies of different prey species, did not show any important differences between the two areas (habitats) for either species (not shown). Consequently, the stomach content data were pooled for individuals caught at both areas for each species in the food composition analyses. Hansen (1949) did not find differences in G. morhua food composition at West Greenland between fjord and coastal areas, and he also pooled stomach content data from the two areas (habitats).

Mean PFI for different prey groups between the two species were statistically tested by regression analyses and Students T-test (parametric tests) in order to get an indication of possible differences in food composition between the two species.

Sample sizes for stomach contents were rather small, especially for G. morhua. Stomach contents of this species have been described from a very large 
number of samples from many areas across the North Atlantic. The major prey types and how they change with predator length, is generally well known. Consequently, the present results for G. morhua were compared with results from literature in order to verify them.

\section{Analyses of catch rate data: Occurrence and density of the two cod species in relation to the feeding studies}

Sampling of cod density data. Data on catch rates by species were recorded for the longline research fishery in the period October-November 1987-89 covering the area from south of Disko Bay to the more southerly parts south of Quaqortoq Inlet (Julianehåb Fjord) at West Greenland, i.e. in Div. 1B, 1C, 1D and $1 \mathrm{E}$, which covered the coastal, inshore (fjord), and offshore areas (Fig. 1, Appendix Table 1). The fishing stations were selected based on a stratified-random design based on Division, area (inshore = fjord, coastal $=$ coast and offshore $=$ bank areas $)$, and three depth zones ( $<100 \mathrm{~m}, 101-200 \mathrm{~m}, 201-300 \mathrm{~m})$ (Appendix Table 1). The standardized longline fishing was performed with lines having 400 hooks each (Mustad $2330 \mathrm{BD}$, no. 6) with gap size of $18 \mathrm{~mm}$, which were mounted on $50 \mathrm{~cm}$ snoods at 2-m intervals and baited with 11-17 cm (mean size $15 \mathrm{~cm}$ ) recently thawed whole capelin (Mallotus villosus). The lines were shot at dawn and hauled after an average fishing time of $4.5 \mathrm{hr}(3.7-7.8 \mathrm{hr}$ ) per set. Catch-per-unit-of-effort (CPUE, catch rate) was recorded as number of fish caught per 100 hooks per $4.5 \mathrm{hr}$ set. Detailed description of the stratification of the research fishery, the gear used, and the design of fishing operations, as well as of the size selectivity of the longline gear used can be found in Hovgård and Riget (MS 1990, 1992) with emphasis on G. morhua, and in Nielsen (MS 1992a,b) with emphasis on G. ogac.

Statistical analysis of cod density data. Cod density was analyzed statistically and described by GLM (General Linear Model) ANOVA tests in relation to species, year, Division, area (habitat) and depth stratum in order to test the hypotheses $\mathrm{h}: 2-\mathrm{h}: 3$ and $\mathrm{h}: 4$. General linear models procedure from the SAS statistical computer package 6.12 (SAS, 1990, 1991b) was used to perform parametric ANOVA tests on mean cod density (dependent variable) by changing the multiplicative model

$$
\begin{aligned}
C P U E_{S P, Y, N S D, H, D S}= & S P_{S P} \times Y_{Y} \times N S D_{N S D} \times H_{H} \\
& \times D S_{D S} \times \varepsilon_{S P, Y, N S D, H, D S}
\end{aligned}
$$

to the linear (additive) model (by logarithmic transformation of CPUE-data)

$$
\begin{aligned}
& \log \left(C P U E_{S P, Y, N S D, H, D S}\right)=S P_{S P}+Y_{Y}+N S D_{N S D}+H_{H} \\
& +D S_{D S}+\log \left(\varepsilon_{S P, Y, N S D, H, D S}\right)
\end{aligned}
$$

To avoid taking the logarithm of zero, $0.001 \mathrm{cod}$ per 100 hooks per $4.5 \mathrm{hr}$ set was added to all the catch rates (CPUE). The fishing effort was weighted by the relative size of each stratum.

The GLM ANOVA was used as this procedure can handle unbalanced data, i.e. where the number of observations varies by cells. The log-transformation was carried out to obtain normally distributed data with equal variances. First the additive Model was tested including all first order interaction effects in order to identify all statistically significant main effects (independent factors) and interaction effects (Models 1 and 2). Models 1 and 2 included both species in order to allow comparative density analyses between species. Model 1 covered only Div. 1D, i.e. the independent factor NSD was removed. This was because the feeding studies on the two species were performed in Div. 1D, and because the best sampling coverage was here. Model 2 covered all Divisions. The resulting reduced models were achieved by successive reduction of non-significant effects (5\% level). In the run of Models 1 and 2 no main effect was removed if the effect was included in a statistically significant interaction effect. Model 3 was run for each species separately (Model 3.1 for G. ogac and Model 3.2 for G. morhua), i.e. the independent factor species was removed here. Furthermore, Model 3 only included main effects in the additive model (no interaction effects). This was done to obtain Model estimates of the (statistically significant) independent factors. The test statistics and the estimates of the ANOVA for each reduced model are presented in the results. The residuals of the models were analyzed by the SAS Univariate procedure (SAS, 1990, 1991a,b) as a test of the errors being normally distributed and having 
equal variances. The tests show that the data were valid and that Models 1, 2, 3.1 and 3.2 describe the density data well on the $1 \%$ level with $50 \%, 74 \%$, $59 \%$ and $28 \%$ of the total variation accounted for, respectively, in the data.

\section{Results}

Most of the individuals of both species measured 35-55 cm (Table 2), however, a relatively larger portion of the sampled $G$. morhua was longer than $55 \mathrm{~cm}$ compared to that of $G$. ogac (Table 2), which only reach a maximum length of $77 \mathrm{~cm}$ (Nielsen, MS 1992a, b). The analyzed G. morhua measured up to $90 \mathrm{~cm}$. The absence of individuals smaller than $30 \mathrm{~cm}$ in the analyses (catches) was due to longline size selectivity as shown by Hovgård and Riget (MS 1990, 1992) for G. morhua and by Nielsen (MS 1992a, b) for G. ogac. Of the 334 analyzed $G$. ogac stomachs 100 were empty (29.9\%) compared to only $4(4.5 \%)$ of the 89 stomachs analyzed from G. morhua (Tables 1 and 2). In relation to bottom depth most individuals with empty stomachs were found in the shallow water fjord areas, however, when pooling for all depth strata the proportion of empty stomachs between the coastal and fjord area, respectively, was not different for any of the species (Table 1). The proportion of empty stomachs was approximately equal for all G. ogac size groups below $50 \mathrm{~cm}$ but declined for the length groups above $50 \mathrm{~cm}$. (Table 2).

Total stomach content, TFI. The mean total food contents, i.e. the TFI, for different length groups and areas are shown in Table 3 for both species. TFI was higher for $G$ ogac (individuals $<55 \mathrm{~cm}$ ) and for all sizes of $G$. morhua in the fjord area compared to the coastal area. For G. ogac the fjord TFI increased with increasing length while there was an opposite tendency in the coastal area (Table 3 ). The mean TFI for smaller G. morhua $<60 \mathrm{~cm}$ were 31.35 and 82.19 , respectively, for the coastal and fjord area (not shown). In the coastal area, the mean TFI for G. morhua increased with length, but this was not apparent from the samples from the fjord area. The generally higher stomach content in the fjord area compared to the coastal area was more pronounced for G. morhua compared to G. ogac (Table 3 ). However, the TFI for G. ogac varied more in the TFI interval 10-100 between stations in the fjord area compared to the coastal area where TFI was between 10-40.

Food composition. The food composition for both species was grouped into main taxonomic prey groups as shown in Tables 4 to 6 and Fig. 3 to 4 , while Appendix Table 2 presents in detail the 53 identified taxonomic prey items to which the food contents could be sorted during laboratory analyses. In general, some prey groups (e.g. Gammaridea, Hyperiidae and Euphausiacea) had high frequency but accounted for only a relatively small portion of total stomach content weight because of small individual weight (Tables 4 to 5). Active feeding on algae, shell gravel, unidentified organic material and small stones was not expected to occur. Furthermore, extensive feeding on Hydrozoa and Bryozoa was neither expected to be significant in periods with presence of abundant alternative food groups (Hansen, 1949). Consequently, these food groups were expected to be "by-catch" in active predation on other food groups and they will not be commented on further (Table 4, Appendix Table 2).

Gadus ogac: The main part of the fish prey for $G$. ogac was found to be capelin (Mallotus villosus) accounting for a relative prey weight between 30-50\% for all predator size groups (Table 4, Fig. 3), however, a clear tendency towards decreasing relative weight of capelin with increasing predator size was found (Fig. $3)$. DoD of capelin in the G. ogac stomach contents was typically between 2-4 (Appendix Table 3) with higher frequencies in the 3-4-groups in total than in the 2-group. As the capelin with a DoD value of 1 and

TABLE 3. TFI estimates for different length groups (cm) of Gadus morhua by survey area.

\begin{tabular}{cllllllllllll}
\hline \hline Species & Area & $30-34$ & $35-39$ & $40-44$ & $45-49$ & $50-54$ & $55-59$ & $60-69$ & $70-79$ & $80-89$ & $>90$ & Mean \\
\hline \multirow{2}{*}{ Gadus } & Coastal & 50.32 & 28.06 & 29.14 & 20.56 & 31.64 & $\ldots$ & $\ldots$ & $\ldots$ & $\ldots$ & $\ldots$ & 31.94 \\
ogac & Fjord & 36.26 & 49.06 & 17.57 & 54.05 & 57.39 & $74.23 *$ & $\ldots$ & $\ldots$ & $\ldots$ & $\ldots$ & 42.87 \\
Gadus & Coastal & $\ldots$ & 20.53 & 23.38 & 27.61 & 34.23 & 50.98 & 84.90 & 3.70 & 184.60 & $\ldots$ & 53.74 \\
morhua & Fjord & $\ldots$ & 54.79 & 182.20 & 56.21 & 52.60 & 65.17 & 69.71 & 26.69 & 81.14 & 107.20 & 73.56 \\
\hline
\end{tabular}

... No observations.

$*>55 \mathrm{~cm}$ 
TABLE 4. Frequencies, relative weights, and the mean PFI estimates for different prey groups found in Gadus ogac stomachs for all individuals analyzed.

\begin{tabular}{llll}
\hline \hline Prey Group & Frequency & Relative Weight & Mean PFI
\end{tabular}

Pisces

$\begin{array}{llll}\text { Mallotus villosus } & 20.7 \% & 44.3 \% & 3.224 \\ \text { Other } & 25.2 \% & 24.3 \% & 1.311\end{array}$

Amphipoda

$\begin{array}{lrrr}\text { Hyperiidae } & 8.7 \% & 0.6 \% & 0.055 \\ \text { Gammaridea } & 19.6 \% & 1.3 \% & 0.093 \\ \text { Caprellidea } & 0.9 \% & 0.0 \% & 0.002\end{array}$

Other Malacostraca

$\begin{array}{lrrr}\text { Euphausiacea } & 9.3 \% & 0.4 \% & 0.030 \\ \text { Crangonidae } & 2.1 \% & 1.6 \% & 0.112 \\ \text { Hippolytidae } & 19.0 \% & 5.1 \% & 0.477 \\ \text { Pandalus } & 8.1 \% & 3.9 \% & 0.237 \\ \text { Natantia } & 8.7 \% & 1.3 \% & 0.091 \\ \text { Brachyura } & 4.2 \% & 4.3 \% & 0.337\end{array}$

\section{Other Crustacea}

Other Crustacea

$33.4 \%$

$3.7 \%$

0.321

\section{Echinodermata}

Holothuroidea

Echinoidea

$1.8 \%$

$6.3 \%$

$1.0 \%$

$0.7 \%$

0.088

Ophiuroidea

$0.3 \%$

$0.0 \%$

0.075

0.000

\section{Mollusca}

Gastropoda

Bivalvia

Cephalopoda
$0.3 \%$

$1.8 \%$

$0.6 \%$

$3.3 \%$

$3.9 \%$

$3.3 \%$
Errantia
Sedentaria
Polychaeta*

Hydrozoa
$0.3 \%$

$1.2 \%$

$6.6 \%$

$8.7 \%$
$0.0 \%$

$0.4 \%$

$0.0 \%$

0.002

0.029

0.001

0.041

0.015

0.041

$0.2 \%$

$0.0 \%$

0.000

Bryozoa

Bryozoa

Other

Unspecified organic material Algae

Unspecified inorganic material

$0.5 \%$

$0.1 \%$

0.004

* Non-classified Polychaeta, because identification is impossible as a consequence of high DoD.
0.314

0.060 
TABLE 5. Frequencies, relative weights, and the mean PFI estimates for different prey groups found in Gadus morhua stomachs for all individuals analyzed.

\begin{tabular}{llc}
\hline \hline Prey Group & Frequency & Mean PFI
\end{tabular}

\section{Pisces}

Mallotus villosus

Other

All together

Amphipoda

Hyperiidae

\section{Other Malacostraca}

Euphausiacea

Crangonidae

Hippolytidae

Pandalus

Natantia

Brachyura
Gammaridea

$57.30 \%$

$28.09 \%$

$75.28 \%$

$15.73 \%$

$16.85 \%$

$26.97 \%$

$1.12 \%$

$19.10 \%$

$15.73 \%$

$17.73 \%$

$38.20 \%$

$22.47 \%$

\section{Echinodermata}

Holothuroidea

Ophiuroidea

$4.49 \%$

$2.25 \%$

\section{Mollusca}

Bivalvia
Cephalopoda

\section{Polychaeta}

Polychaeta
$15.73 \%$

$1.12 \%$

0.280

0.013
0.366

0.111

0.008

3.598

1.149

0.071

0.116

0.340

0.010

0.225

0.107

0.107

3.963

.

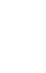




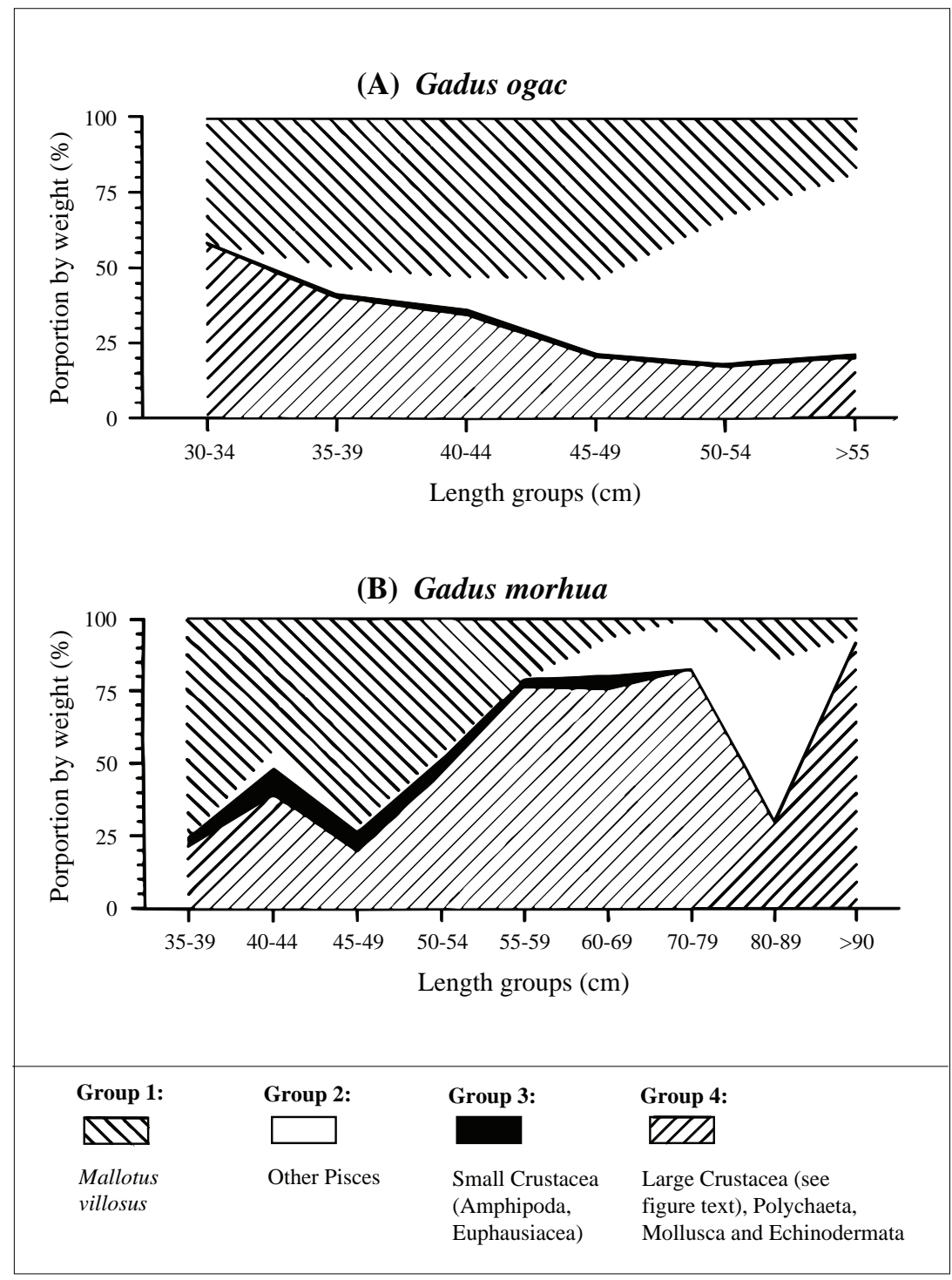

Fig. 3. Relative contributions in weight (calculated as the PFI for each group divided by the total PFI for all prey groups) of the main prey groups in total stomach content for different predator size groups (5-cm length groups) of (A) Gadus ogac and (B) Gadus morhua, in Div. 1D, West Greenland, in the autumn period. Prey group 1: Mallotus villosus (Capelin). Prey group 2: Other Pisces species (and Cephalopoda which is not important). Prey group 3: Small Crustacea: Amphipoda (Gammaridea, Caprellidea, Hyperidae) and Euphausiacea. Prey group 4: Large Crustacea (Crangonidae, Hippolytidae, Pandalus, Natantia, Brachyura), Polychaeta, Mollusca and Echinodermata.

capelin with hook marks or identified as egg bearing females were deleted from the stomach contents analyses, the influence of bait most likely was insignificant here. The relative importance of the rest of the fish prey besides capelin showed an increasing tendency with predator length, where the demersal species Myoxocephalus sp., Triglops sp., Cottidae sp.,
Aspidophoroides monopterygius and Artediellus sp. were important components. Fish prey was present in $40 \%$ of the G. ogac stomachs (Tables 4 and 6). Also the frequency of fish prey increased with increasing predator length (the latter not presented). Overall there were approximately equal frequencies of capelin and other fish species (Table 4). Cephalopoda was found 


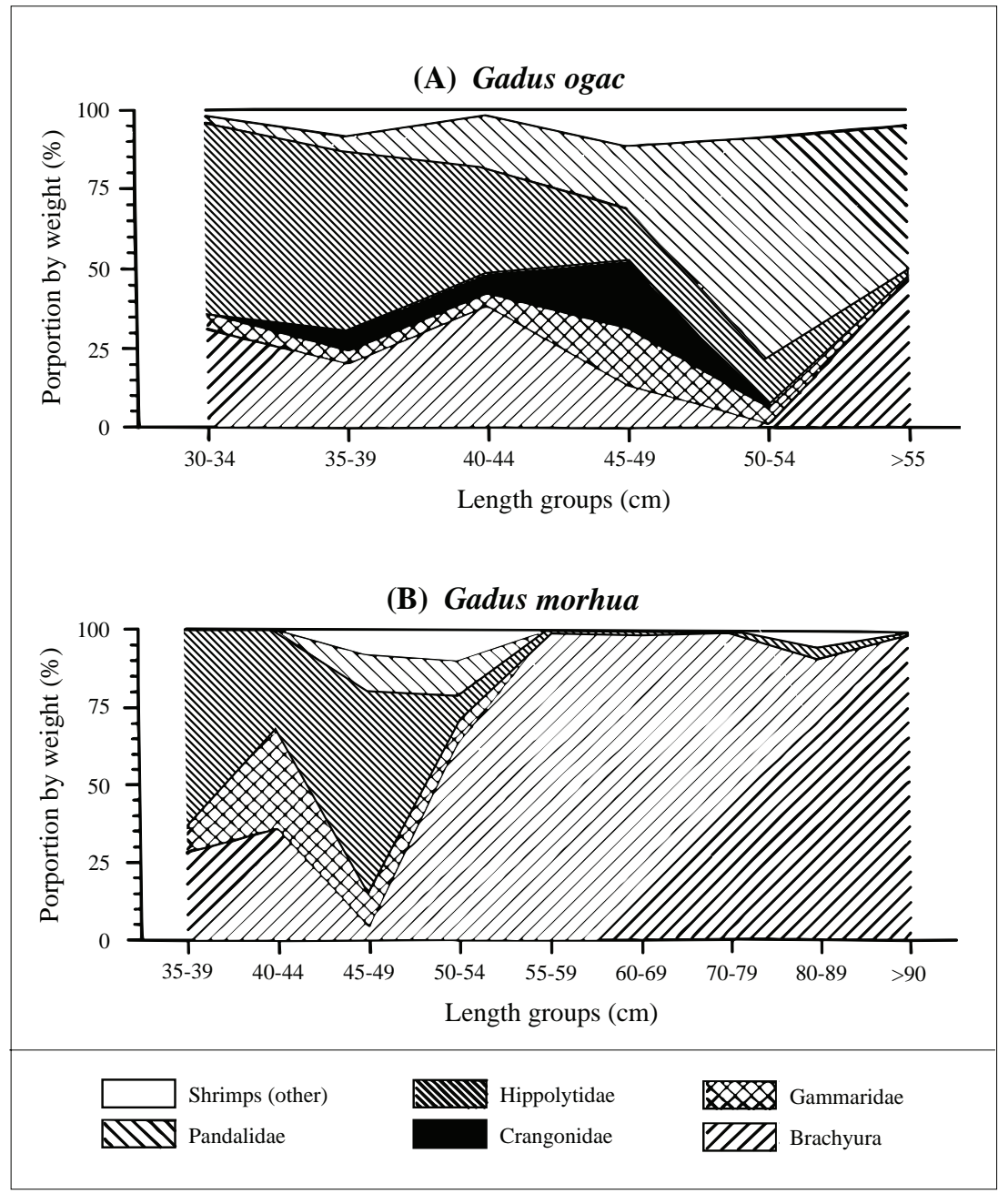

Fig. 4. Relative contributions in weight of different Crustacea prey groups for (A) Gadus ogac and (B) Gadus morhua, of different size groups (5-cm length groups) calculated as the PFI for each group divided by the total PFI for all Crustacea. The values represent a total for all stomachs analyzed from the sampling in Div. $1 \mathrm{D}$, West Greenland, in the autumn period.

only infrequently (Table 4) and only accounted for a very small part of the total weight of stomach contents for all predator size groups.

The relative importance in weight of large Crustacea, Polychaeta, Mollusca and Echinodermata, i.e. the group of larger invertebrate prey, decreased as fish prey increased with increasing predator length (Fig. $3)$. This group occurred with highest frequency in all stomachs analyzed (Tables 4 and 6), and had nearly the same relative frequency for all predator size groups (not shown). The (large) Crustacea was the most important food group in weight for that part of the prey, which did not consist of fish for all predator length groups. The Crustacea contributed with approximately $85 \%$ of total PFI for that part, and about $25 \%$ of total PFI of the total food amount. (Tables 4 and 6, Fig. 3 to 4). The Echinodermata and Polychaeta accounted for $8 \%$ and $5 \%$, respectively, while Mollusca, mainly represented by Bivalvia, accounted for $2 \%$ (Tables 4 and 6, Fig. 3). For Crustacea, more than $12 \%$ of the food content in weight was shrimps (Hippolytidae, Pandalus, Natantia, Crangonidae). Shrimp of the families Pandalidae and Crangonidae increased in importance with increasing predator length, while the opposite tendency was seen for the family Hippolytidae. The crabs (Brachyura) showed no tendencies in PFI according to predator size. (Table 4, Fig. 4). Among 
the Echinodermata the Echinoidea was not important by weight but relatively frequent, while the relatively infrequent Holothuroidea had higher relative weight than the Echinoidea because of the relatively high individual weight. By weight, the Polychaeta only exceeded $1 \%$ of the total stomach content for the predator $(G$ ogac) size groups $35-50 \mathrm{~cm}$ with a maximum of $2.5 \%$ in $40-44 \mathrm{~cm}$. In general, the Polychaeta prey was present in $10 \%$ of all predator length groups. Errantia accounted for three times the relative weight in the food content compared to Sedentaria, but they were equally frequent for all predator size groups (Table 4, Fig. 3).

Small Crustacea contributed only a relatively small part of the total stomach content by weight. This group had the lowest average relative prey weight and was also generally infrequent for all predator size groups. (Fig. 3 to 4, Tables 4 and 6). However, there was a tendency towards increasing frequency with increasing predator length with maxima of $20-25 \%$ for the largest predator size groups (not shown).

Gadus morhua. Fish prey accounted by weight for nearly half of the total PFI estimated for G. morhua and was found with a relative frequency of more than $75 \%$ in the stomachs. Capelin represented by weight the highest PFI of all single prey groups and occurred with a relative frequency of more than $57 \%$. (Tables 5 and 6 , Fig 3). Fish prey showed decreasing importance with increasing predator length (Fig. 3). Up to $60 \mathrm{~cm}$ predator ( $G$. morhua) length, the capelin was dominant but for predators larger than $60 \mathrm{~cm}$ the importance of capelin prey decreased. The fish prey group of these large predator size groups consisted mainly of $G$. morhua, eelpouts (Lycodes spp.) and American plaice (Hippoglossoides platessoides). Cannibalism on small cod ( $G$. morhua) seemed to be rather frequent for large $G$. morhua. Only 5 out of the total 81 capelin found in the stomachs of $G$. morhua smaller than $60 \mathrm{~cm}$ had a DoD value of 2 or less (Appendix Table 3). The majority of the capelin prey had a DoD of 4 or 5 , i.e. was digested to a relatively high degree. Consequently, bait residuals were not considered influential to the results.

For G. morhua the fish prey and the group of large invertebrate prey had nearly the same relative weight and were equally frequent (Tables 5 and 6, Fig. 3) as a total for all stomachs analyzed, and also for all length groups separately (not shown). Small Crustacea was half as frequent as the two former groups and accounted only for $4 \%$ of the sum of the PFI for all prey groups together (Tables 5 and 6). Small Crustacea was not found in the stomachs of G. morhua larger than $70 \mathrm{~cm}$, while no trends were found in frequency for the small Crustacea prey group with predator length for smaller G. morhua (Fig. 3 and 4).

Concerning the large Crustacea, Polychaeta, Mollusca and Echinodermata, i.e. the group of larger invertebrates for G. morhua, the PFI for Crustacea amounted $88 \%$ of the total PFI for this group, and Crustacea was also most frequent here (Table 5, Fig. 3). Bivalvia and Polychaeta had approximately equal weight indices (5\%), while the Echinodermata was of minor importance with only $2 \%$ contribution to the total PFI. Polychaeta and Echinodermata were also relatively infrequent in occurrence. The importance of the prey group of large invertebrates increased with increasing predator length for predators smaller than $70 \mathrm{~cm}$, while it decreased in the 80-89 $\mathrm{cm}$ predator length group, and then increased again and reached a relative maximum for predators larger than $90 \mathrm{~cm}$ (Fig. 3). Even when taking into account possible influence of the relatively smaller sample sizes of the two latter predator length groups there was a general tendency towards increasing importance of this prey group with increasing predator length for the total predator size range. The Crustacea was by weight completely dominated by the larger groups, i.e. Brachyura, for predators larger than $50-54 \mathrm{~cm}$, while shrimps (mostly Hippolytidae) were relatively important for fish smaller than this size. The Crangonidae was not important prey for any predator length groups, while the Gammaridea accounted for $7-33 \%$ in weight of the total Crustacea stomach content for predators less than $55 \mathrm{~cm}$ in length but were not important for larger G. morhua (Fig. 4, Table 5).

Comparison of Gadus ogac and Gadus morhua diet. All prey groups found in G. morhua were also found in $G$. ogac stomachs. Fish prey, and especially capelin, was important for both species in all length groups. For G. morhua smaller than around $55 \mathrm{~cm}$ the major part of the food constituted capelin, while capelin accounted for $25-50 \%$ of the food for $G$. ogac smaller than $44 \mathrm{~cm}$, reflecting the tendency towards large invertebrate prey being slightly more important food for G. ogac of these size-classes compared to G. morhua. In general, prey size increased with increasing predator length, however, while fish became dominant prey for larger G. ogac, large Crustacea (Brachyura) became primary food for larger G. morhua. For both species the most important large invertebrate prey was Crustacea, however, the proportion of Polychaeta and 
Mollusca was relatively higher for G. morhua compared to $G$. ogac for the large invertebrate prey group. The Crustacea food of all size groups of $G$. ogac was dominated by shrimps, especially Hippolytidae for smaller individuals and Pandalidae for larger individuals, while Crustacea prey for G. morhua was dominated by shrimps (Hippolytidae) for smaller individuals and Brachyura for larger individuals. In general, small Crustacea was not important diet for any of the size groups investigated of both species even though this group was more than twice as frequent for G. morhua than for G. ogac (Table 6). Comparative analyses of PFI for the different prey groups of the two species (Fig. 5) indicated the diet of G. ogac was not statistically different from that of the coexisting G. morhua at West Greenland.
Distribution and density of G. morhua and G. ogac in West Greenland waters

The geographic distribution of the fishery is shown in Fig. 1, and the fishing effort by stratum is shown in Appendix Table 1. Calculated mean CPUE values per stratum on which ANOVA tests were performed are presented in Table 7, while the results and output statistics of the multivariate analyses of variance performed on density patterns are shown in Table 8 . The GLM Models 1, 2, 3.1 and 3.2 described 50\%, $74 \%, 59 \%$ and $28 \%$, respectively, of the variation in catch rate data, and consequently described the density and distribution patterns for the two cod species at West Greenland generally well (Table 8). The reason Model 3.2 for $G$. morhua only described about one third of the
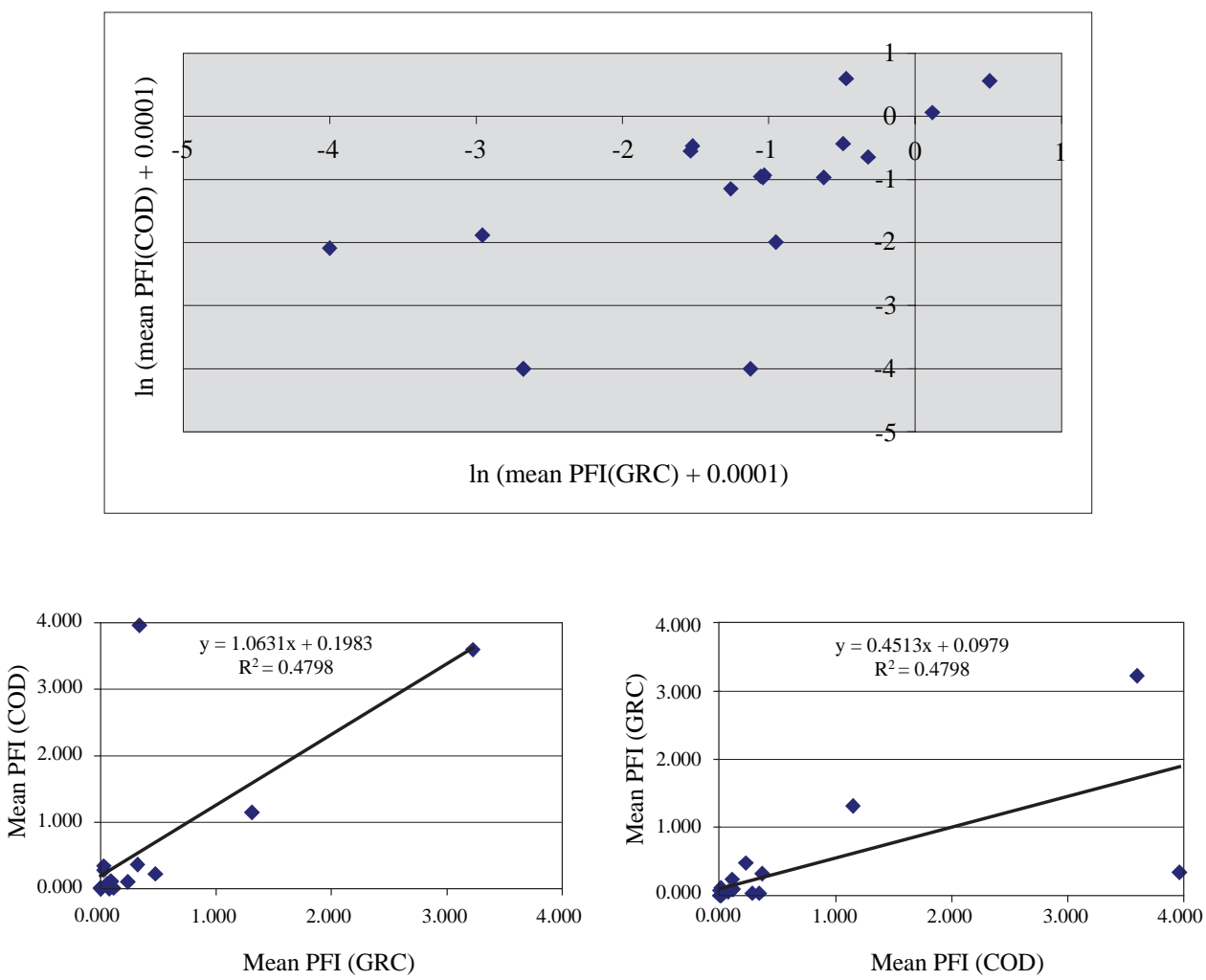

Fig. 5. Linear regressions of mean PFI for the different prey groups between Gadus ogac (GRC) and Gadus morhua (COD) performed with exchange of axes for the species specific mean PFI, respectively. According to Students T-test the slopes in both cases are not statistically different from 1 (at the 5\% level). The $95 \%$ and $5 \%$ fractiles for the slopes are 0.94 and 1.18 for the estimated slope of 1.06 (standard deviation 0.06 ), and -0.25 and 1.15 for the estimated slope of 0.45 (standard deviation 0.35 ), for G. ogac and G. morhua respectively. The slopes in both cases are not different from 1 indicating that the diets of the two species are not significantly different. 
TABLE 7. Mean CPUE (number of individuals per 100 hooks per 4.5 hour setting) of Gadus ogac and Gadus morhua, by year, NAFO Division, area (Offshore, Coastal and Inshore) and depth stratum during the 1987-89 longline surveys.

\begin{tabular}{|c|c|c|c|c|c|c|c|c|c|}
\hline \multirow{2}{*}{$\begin{array}{l}\text { NAFO } \\
\text { Division }\end{array}$} & \multirow{2}{*}{$\begin{array}{l}\text { Depth } \\
\text { stratum } \\
(\mathrm{m})\end{array}$} & \multicolumn{3}{|c|}{1987} & \multicolumn{3}{|c|}{$\begin{array}{l}\text { Year } \\
1988\end{array}$} & \multicolumn{2}{|c|}{1989} \\
\hline & & Offshore & Coastal & Inshore & Offshore & Coastal & Inshore & Coastal & Inshore \\
\hline \multicolumn{10}{|c|}{ Greenland cod (Gadus ogac) } \\
\hline \multirow{4}{*}{ 1B } & $0-100$ & $\ldots$ & $\ldots$ & $\ldots$ & $\ldots$ & $\ldots$ & $\ldots$ & 3.4 & 0.2 \\
\hline & $101-200$ & $\ldots$ & $\ldots$ & $\ldots$ & $\ldots$ & $\ldots$ & $\ldots$ & 0.4 & 4.0 \\
\hline & $201-300$ & $\ldots$ & $\ldots$ & $\ldots$ & $\ldots$ & $\ldots$ & $\ldots$ & 0.5 & 4.8 \\
\hline & $0-100$ & 3.8 & 7.5 & 3.5 & 2.8 & 4.6 & 2.0 & 5.0 & 4.8 \\
\hline \multirow[t]{3}{*}{$1 \mathrm{C}$} & $101-200$ & 1.0 & 5.1 & 0.4 & 0.4 & 3.8 & 3.4 & 3.3 & 8.6 \\
\hline & $201-300$ & 0.3 & 0.6 & $\ldots$ & 0.0 & 1.9 & 0.1 & 1.8 & 1.4 \\
\hline & $0-100$ & 1.5 & 11.4 & 9.0 & 3.3 & 8.6 & 3.3 & 8.1 & 4.9 \\
\hline \multirow[t]{3}{*}{$1 \mathrm{D}$} & $101-200$ & 0.9 & 2.3 & 6.4 & 1.3 & 6.5 & 4.2 & 11.6 & 9.8 \\
\hline & $201-300$ & 0.4 & 9.9 & 6.0 & 0.0 & 8.7 & 2.0 & 12.6 & 10.3 \\
\hline & $0-100$ & 0.0 & 5.9 & 9.0 & 0.0 & 1.2 & 12.7 & 6.5 & 3.0 \\
\hline \multirow[t]{2}{*}{$1 \mathrm{E}$} & $101-200$ & 0.2 & 1.6 & 1.1 & $\ldots$ & 8.0 & 3.0 & 7.2 & 5.2 \\
\hline & $201-300$ & 0.0 & 0.6 & 2.6 & 0.0 & 3.0 & $\ldots$ & 0.7 & 0.7 \\
\hline \multicolumn{10}{|c|}{ Atlantic cod (Gadus morhua) } \\
\hline \multirow{4}{*}{$1 \mathrm{~B}$} & $0-100$ & $\ldots$ & $\ldots$ & $\ldots$ & $\ldots$ & $\ldots$ & $\ldots$ & 0.0 & 2.2 \\
\hline & $101-200$ & $\ldots$ & $\ldots$ & $\ldots$ & $\ldots$ & $\ldots$ & $\ldots$ & 0.0 & 1.8 \\
\hline & $201-300$ & $\ldots$ & $\ldots$ & $\ldots$ & $\ldots$ & $\ldots$ & $\ldots$ & 0.0 & 0.1 \\
\hline & $0-100$ & 1.0 & 2.3 & 2.1 & 0.3 & 9.4 & 1.7 & 0.5 & 1.2 \\
\hline \multirow[t]{3}{*}{$1 \mathrm{C}$} & $101-200$ & 0.5 & 0.8 & 0.0 & 0.0 & 4.3 & 1.7 & 0.6 & 0.5 \\
\hline & $201-300$ & 0.1 & 0.0 & $\ldots$ & 0.0 & 2.9 & 0.2 & 0.6 & 0.4 \\
\hline & $0-100$ & 12.0 & 7.2 & 1.1 & 9.9 & 7.0 & 0.1 & 1.0 & 1.1 \\
\hline \multirow[t]{3}{*}{$1 \mathrm{D}$} & $101-200$ & 8.4 & 3.8 & 0.1 & 11.0 & 3.3 & 0.2 & 0.5 & 0.3 \\
\hline & $201-300$ & 2.5 & 2.5 & 0.2 & 3.4 & 1.5 & 0.1 & 0.9 & 0.2 \\
\hline & $0-100$ & 26.0 & 6.7 & 0.4 & 23.4 & 0.3 & 3.6 & 2.2 & 0.5 \\
\hline \multirow[t]{2}{*}{$1 \mathrm{E}$} & $101-200$ & 14.4 & 1.5 & 0.1 & $\ldots$ & 0.0 & 0.0 & 2.0 & 0.3 \\
\hline & $201-300$ & 2.1 & 1.4 & 0.3 & 0.0 & 0.9 & $\ldots$ & 0.3 & 0.2 \\
\hline
\end{tabular}

... No observations.

variation in catch rate data was a result of the occurrence of a highly significant first order interaction effect between area and Division in the G. morhua density pattern. If this interaction effect had been included in the model it would have explained $53 \%$ of the total variation in the data (not shown). However, in order to estimate the main effects influencing fish density patterns in Model 3, only the main effects were included in here.

The test output from all Models, i.e. Model 1 (both species, all Divisions), Model 2 (both species, Div. 1D alone) as well as Models 3.1-3.2 (each species analyzed separately, i.e. G. ogac and G. morhua, respectively, in all Divisions), shows that there were no statistical differences between years (Table 8). Neither were there any significant first order interaction effects between year and any other independent factor influencing fish density. Thus, the density patterns for both cod species in West Greenland waters were consistent between years in the period 1987-89. Models 1 and 2 both show that the species effect was statistically insignificant on the 5\% level (Table 8). However, in both Models there were a highly significant interaction effect between species and area. Consequently, even though there did not appear to be any differences in general distribution and density between species, there were some distinct differences in density patterns for each of the two species in different areas. From estimation of these dissimilarities in Models 3.1 and 3.2 (Table 8) it appears that $G$. ogac has a mainly coastal and inshore distribution with no significant differences in density between these two areas, while in general having a relatively low density on the banks (offshore). In comparison $G$. morhua has a mainly offshore and coastal distribution and occurs only with relatively low 
TABLE 8. The descriptive statistics of the GLM analyses of variance and estimated parameters for each model. The sum of squared deviations for the various dependent effects are of type III sum of squares for all models (SAS, 1990, 1991a and b), i.e. independent of the order of the effects in the models. The descriptive statistics of the test of normality are given for each model.

\begin{tabular}{|c|c|c|c|c|c|c|}
\hline Source & Model & $\begin{array}{c}\text { Degrees of } \\
\text { Freedom }\end{array}$ & $\begin{array}{l}\text { Sum of } \\
\text { squares }\end{array}$ & $\mathrm{F}$ & Probability $>$ F & $r^{2}$ \\
\hline \multicolumn{7}{|l|}{ Descriptive statistics } \\
\hline Model & 1 & 19 & 99.69 & 6.92 & 0.0001 & 0.50 \\
\hline Error & 1 & 130 & 98.62 & & & \\
\hline Corrected total & 1 & 149 & 198.31 & & & \\
\hline Model & 2 & 11 & 21.99 & 9.24 & 0.0001 & 0.74 \\
\hline Error & 2 & 36 & 7.79 & & & \\
\hline Corrected total & 2 & 47 & 29.77 & & & \\
\hline Model & 3.1 & 9 & 48.40 & 10.40 & 0.0001 & 0.59 \\
\hline Error & 3.1 & 65 & 32.62 & & & \\
\hline Corrected total & 3.1 & 74 & 82.02 & & & \\
\hline Model & 3.2 & 9 & 29.82 & 2.79 & 0.0078 & 0.28 \\
\hline Error & 3.2 & 65 & 77.10 & & & \\
\hline Corrected total & 3.2 & 74 & 106.92 & & & \\
\hline Species & 1 & 1 & 3.12 & 4.11 & 0.0500 & \\
\hline NAFO Division & 1 & 3 & 19.88 & 8.73 & 0.0001 & \\
\hline Area (habitat) & 1 & 2 & 12.59 & 8.30 & 0.0004 & \\
\hline Depth stratum & 1 & 2 & 17.71 & 11.67 & 0.0001 & \\
\hline Species * Area & 1 & 2 & 24.20 & 15.95 & 0.0001 & \\
\hline NAFO Div. * Area & 1 & 5 & 14.48 & 3.82 & 0.0029 & \\
\hline Depth stratum * Area & 1 & 4 & 7.82 & 2.58 & 0.0405 & \\
\hline Species & 2 & 1 & 0.56 & 2.58 & 0.1168 & \\
\hline Area (habitat) & 2 & 2 & 3.00 & 6.94 & 0.0028 & \\
\hline Depth stratum & 2 & 2 & 2.67 & 6.17 & 0.0050 & \\
\hline Species $*$ Area & 2 & 2 & 12.57 & 29.06 & 0.0001 & \\
\hline Depth stratum * Area & 2 & 4 & 2.51 & 2.90 & 0.0351 & \\
\hline Year & 3.1 & 2 & 1.12 & 1.09 & 0.3434 & \\
\hline NAFO Division & 3.1 & 3 & 8.72 & 5.62 & 0.0017 & \\
\hline Area (habitat) & 3.1 & 2 & 27.60 & 26.68 & 0.0001 & \\
\hline Depth stratum & 3.1 & 2 & 6.58 & 6.36 & 0.0030 & \\
\hline Year & 3.2 & 2 & 1.83 & 0.77 & 0.4669 & \\
\hline NAFO Division & 3.2 & 3 & 13.56 & 3.81 & 0.0140 & \\
\hline Area (habitat) & 3.2 & 2 & 1.64 & 0.69 & 0.5040 & \\
\hline Depth stratum & 3.2 & 2 & 12.01 & 5.06 & 0.0090 & \\
\hline
\end{tabular}

\begin{tabular}{llllll}
\hline \hline Model Parameter & Group & Estimate & T for H0; Par. $=0$ & Probability $>|\mathrm{T}|$ & Std. Error
\end{tabular}

Logarithmic transformed estimates of parameters from main effect models (Models 3.1 and 3.2)

$\begin{array}{llcrrrr}3.1 & \text { Intercept } & \text { Intercept } & -1.75 & -5.43 & 0.0001 & 0.32 \\ 3.1 & \text { Year } & 1987 & -0.06 & -0.24 & 0.8132 & 0.23 \\ 3.1 & & 1988 & -0.30 & -1.29 & 0.2033 & 0.23 \\ 3.1 & & 1989 & 0 & & & \\ 3.1 & \text { NAFO Division } & 1 \mathrm{~B} & -0.16 & -0.46 & 0.6503 & 0.36 \\ 3.1 & & 1 \mathrm{C} & 0.43 & 1.98 & 0.0518 & 0.22\end{array}$


TABLE 8. (Continued). The descriptive statistics of the GLM analyses of variance and estimated parameters for each model. The sum of squared deviations for the various dependent effects are of type III sum of squares for all models (SAS, 1990, 1991 a and b), i.e. independent of the order of the effects in the models. The descriptive statistics of the test of normality are given for each model.

\begin{tabular}{|c|c|c|c|c|c|c|}
\hline Model & Parameter & Group & Estimate & $\mathrm{T}$ for $\mathrm{H} 0 ;$ Par. $=0$ & Probability $>|\mathrm{T}|$ & Std. Error \\
\hline
\end{tabular}

Logarithmic transformed estimates of parameters from main effect models (Models 3.1 and 3.2)

\begin{tabular}{|c|c|c|c|c|c|c|}
\hline 3.1 & NAFO Division & 1D & 0.80 & 3.74 & 0.0004 & 0.21 \\
\hline 3.1 & & $1 \mathrm{E}$ & 0 & & & \\
\hline 3.1 & Area (habitat) & Coastal & 1.61 & 6.96 & 0.0001 & 0.23 \\
\hline 3.1 & & Inshore & 1.50 & 6.33 & 0.0001 & 0.24 \\
\hline 3.1 & & Offshore & 0 & & & \\
\hline 3.1 & Depth stratum & $0-100 \mathrm{~m}$ & 0.64 & 3.13 & 0.0026 & 0.20 \\
\hline 3.1 & & $101-200 \mathrm{~m}$ & 0.64 & 3.08 & 0.0030 & 0.21 \\
\hline 3.1 & & $201-300 \mathrm{~m}$ & 0 & & & \\
\hline 3.2 & Intercept & Intercept & -0.43 & -0.89 & 0.3794 & 0.49 \\
\hline 3.2 & Year & 1987 & 0.04 & 0.12 & 0.9034 & 0.35 \\
\hline 3.2 & & 1988 & -0.31 & -0.89 & 0.3800 & 0.35 \\
\hline 3.2 & & 1989 & 0 & & & \\
\hline 3.2 & NAFO Division & $1 \mathrm{~B}$ & -1.25 & -2.28 & 0.0260 & 0.55 \\
\hline 3.2 & & $1 \mathrm{C}$ & -0.21 & -0.66 & 0.5136 & 0.33 \\
\hline 3.2 & & $1 \mathrm{D}$ & 0.46 & 1.43 & 0.1562 & 0.32 \\
\hline 3.2 & & $1 \mathrm{E}$ & 0 & & & \\
\hline 3.2 & Area (habitat) & Coastal & -0.12 & -0.35 & 0.7248 & 0.35 \\
\hline 3.2 & & Inshore & -0.38 & -1.07 & 0.2896 & 0.36 \\
\hline 3.2 & & Offshore & 0 & & & \\
\hline 3.2 & Depth stratum & $0-100 \mathrm{~m}$ & 0.92 & 2.97 & 0.0042 & 0.31 \\
\hline 3.2 & & $101-200 \mathrm{~m}$ & 0.17 & 0.55 & 0.5811 & 0.31 \\
\hline 3.2 & & $201-300 \mathrm{~m}$ & 0 & & & \\
\hline
\end{tabular}

\begin{tabular}{lllll}
\hline Variable & Model & $\mathrm{N}$ & $\mathrm{W}:$ Normal & Probability $<\mathrm{W}$ \\
\hline Test of normality : & & & & \\
Residuals & 1 & 150 & 0.9246 & 0.0001 \\
& 2 & 48 & 0.8938 & 0.0004 \\
& 3.1 & 75 & 0.9682 & 0.0558 \\
& 3.2 & 75 & 0.9370 & 0.0010 \\
\hline
\end{tabular}

density inshore (Table 8). Although this describes the general density pattern for the two species, then presence of a first order interaction effect between area and Division resulted in slight differences in the area specific density patterns between the different Divisions at West Greenland (Table 8). However, this interaction effect accounted for only $7 \%$ of the total variation in data on average for both species (Model 1). The area specific differences in distribution were much more pronounced for G. morhua than for G. ogac, as the interaction effect between area and Division accounts for
$25 \%$ for $G$. morhua and only $11 \%$ for $G$ ogac of the total variation in catch rate data analyses conducted separately for each species and including all significant first order interaction effects (not shown). This was because G. morhua in Div. 1B (Northwest Greenland) showed an opposite tendency in density compared to that in other Divisions in having much higher inshore than coastal density in Div. 1B.

The overall mean density of $G$. morhua was higher than for G. ogac in West Greenland waters (not shown). 
In general both species showed highest density in the central part, i.e. in Div. 1D (Table 8). Consequently, there was a relatively high degree of (statistically significant) overlap in distribution between the species here, and especially in the coastal areas as shown above (Table 8). In general, the more boreal G. morhua showed gradually increasing density towards the south, i.e. from Div. 1B to 1E, while the more arctic G. ogac occurred with highest density in the northern Div. 1D and $1 \mathrm{C}$ (Table 8).

Gadus ogac was typically distributed in the more shallow water areas at West Greenland with bottom depths between 0-100 $\mathrm{m}$ and 101-200 $\mathrm{m}$ and with equal densities in these two depth strata, while the density in deeper sea water from 201-300 m was significantly lower (Table 8). Gadus morhua also showed a mainly shallow water distribution with highest densities in the depth stratum 0-100 m, and with typically lower densities in the deeper sea strata 101-200 m and 201$300 \mathrm{~m}$. There were no significant first order interaction effects between species and depth stratum for the tested Models 1 and 2 (Table 8 shows results from the reduced Models, i.e. only including the significant effects among all the main and first order interaction effects tested by the Models). Furthermore, the interaction effects between depth stratum and area only accounted for a small part of the total variation in the catch rate data (Models 1 and 2, Table 8), and were not significant for G. morhua alone and only slightly significant for G. ogac separately (not shown).

\section{Discussion}

Feeding analyses. The existing reports of $G$ ogac diet (see Nielsen and Morin, 1993) within its distribution area (covering Greenland, Canada and Alaska) indicate that this species prey on a broad variety of both demersal and pelagic species. This appears from systematic identification of $G$. ogac stomach contents in studies giving qualitative descriptions of prey species (Jensen 1909a and 1909b, 1948) through estimates of relative frequencies of occurrence of prey groups (Morin and Dodson, 1986; Morin et al., 1991) to estimates of relative weight or relative volumes of prey groups in relation to total stomach content (Chaput, MS 1981; Mikhail and Welch, 1989; as well as the present study). These studies show in general that for larger size groups G. ogac show preference for fish, and its primary food is capelin when available, while Crustacea is the second most important food group followed by Polychaeta, to which groups the G. ogac can switch, when fish prey are not available. This general picture is supported by the results from the present study, where G. ogac was found to exploit a wide variety of food items and also preyed on all food types found for the coexisting $G$. morhua, which is well known to be an opportunistic feeder in Greenland waters (Hansen, 1949; Tiedtke, 1988). Gadus ogac was found to exploit even more prey groups than G. morhua, i.e. Caprellidea and Echinoidea. This indicates that G. ogac can also be classified as an opportunistic feeder.

Even though some differences existed in diet between the same size groups of the two species no statistical differences in overall diet of $G$ ogac and G. morhua in Greenland waters were found (present study). Consequently, the two species very likely compete for food when overlapping in size and geographic distribution.

The identified main prey groups, and how these change with predator size, for G. morhua in the present study are generally in accordance with results from other feeding studies on this species from many areas across the Northwest Atlantic: Greenland (Hansen, 1949; Köster and Schober, MS 1990); Iceland (Palsson, 1983; Magnusson and Palsson, 1989; Palsson and Björnsson, MS 1993); Labrador and Newfoundland in Canada (Lilly, 1994); Flemish Cap (Paz et al., MS 1991). Hansen (1949) concluded from analyses of 254 G. morhua stomachs from the bank areas and 1413 stomachs from the coastal and fjord areas at West Greenland, that this species is omnivorous, and prey on both pelagic and demersal species. In agreement with the results of the present study, Hansen (1949) found that fish and various pelagic and bathypelagic Crustacea (Pandalus borealis especially, Euphausidae, Amphipoda (Themisto)) and demersal animals as crabs (Hyas) and Polychaeta were the principal food. On the banks, crabs (Hyas) dominated the diet, then came other Crustacea (Pandalus sp., Amphipoda, and Euphausiacea) followed by fish and Polychaeta. In the coastal and fjord areas, the fish were the most important food (capelin (Mallotus villosus) and lance (Ammodytes)) even though fish prey to some degree were seasonal (June to September). Then followed other Crustacea (Pandalus sp., Amphipoda and Euphausiacea) while crabs (Hyas) and Polychaeta were relatively rare here (Hansen, 1949).

Comparison of diet between G. ogac and G. morhua in the autumn period in West Greenland waters. The present results show that for both species, the highest mean TFI was found in the inshore area compared to the coastal area, and the mean TFI in the fjord area was approximately the same for the two 
species. The results show a general overlap in diet in that all prey groups found for G. morhua were also found in $G$. ogac stomachs. Although differences in prey preferences for different predator size groups did occur between the two species, there were no statistical differences found in the general food composition for the two coexisting species. This leads to acceptance of hypothesis h: 1 .

No important differences in diet for G. ogac and $G$. morhua between the inshore and coastal areas (habitats) were found. However, potential smaller differences would only have been distinct if a higher number of stomachs had been analyzed. Hansen (1949) found no differences in G. morhua food composition between inshore and coastal areas at West Greenland, and consequently he pooled stomach content data for the two areas. Chaput (MS 1981) found some geographical variances in diet for $G$. ogac caught at two inshore Labrador localities even though there was a general overlap in diet between these. Mikhail and Welch (1989) could not find any significant differences in the diet of $G$. ogac caught at two inshore localities in Hudson Bay.

In the present study, differences in diet between the inshore and coastal areas were also not expected for the following reason: The Godthåb Fjord is a relatively large and deep fjord system with relatively high water renewal from offshore and coastal areas, and because of the very similar hydrographic conditions no important differences in the fauna, i.e. in the cod food diversity and availability, between the fjord and the coastal (and offshore) areas were expected in the investigated depth ranges. All fish prey species and most invertebrate prey groups found for G. ogac and $G$. morhua are known to occur in both coastal and inshore areas (Muus et al., 1981; Høpner Petersen and Smidt, 1981; personal investigations in the journals of Greenland Fisheries Research Institute; Nielsen and Morin, 1993; and other literature searches).

Furthermore, as G. ogac is also distributed in brackish water environments and is able to prey on solely brackish water prey species such as Coregonis clupeaformis, C. artedii and Catostomus commersoni (Morin and Dodson, 1986; Morin et al., 1991, 1992), the species has the potential to shift diet in relation to different geographic localities and habitats.

Distribution and density analyses in relation to feeding analyses. The present results show that the distribution of G. ogac and G. morhua overlap at West Greenland, and that the density patterns of the two species are not very different over a broad spectra of strata, i.e. there exists a statistically significant high degree of coexistence in some areas off West Greenland. Highest overlap in distribution was found in the central part and in the coastal areas at localities with bottom depths between $0-200 \mathrm{~m}$. These distribution patterns were found to be consistent for all years during the investigation period 1987-89. This leads us to accept the hypotheses h:2 and h:3. The density analyses were performed on fish of similar size of both species, however, the catch rate data were not subdivided by size group in the analyses. Consequently, possible size specific differences in distribution between the two species were not investigated and might occur. Even though smaller differences in food composition between different size groups of the two species might to some degree reduce the competition for food, a broad overlap in diet and feeding areas of the two species was found, and they both have been shown to be opportunistic feeders. Based on this and the statistically significant broad overlap in distribution, we conclude that the two species most likely are interspecific competitors for food and space at West Greenland. In conclusion this indicates that hypothesis $\mathrm{h}: 4$ should be accepted.

The influence and possible impacts of interspecific competition or predation between the two species (in form of interspecific predation or/and cannibalism) is relevant and important from a resource management point of view as G. morhua is a commercially very important fishery resource and because $G$. ogac is also an exploited resource with the potential of further exploitation in West Greenland waters (Nielsen, MS 1992a, MS 1992b; Nielsen and Morin, 1993; ICES, 2000; Buch et al., 1994). A high degree of interspecific competion has the potential of influencing the stock dynamics and the stock abundances of the two species, which may affect the fishery resource availability. The interspecific interactions are expected to have highest influence in the more centrally located areas off West Greenland because G. morhua is near its northern distribution boundary in the northern part of the survey area. The north-south distribution patterns of both species have been shown to have a periodic character and to change over time according to sea temperature changes at West Greenland (Jensen, 1948; Hansen, 1949; Buch et al., 1994). Despite this, the two species have historically been reported to occur in the same areas (especially the central part) at West Greenland (Jensen, 1948; Hansen, 1949; Buch et al., 1994) and probably permanently coexist here.

Future studies. A thorough and detailed description of the character of likely interspecific 
competition patterns between G. ogac and G. morhua in West Greenland waters does demand more comprehensive studies than performed here. The comparative feeding ecology studies reported here are based on only limited data. For example the sampling coverage does not allow for comparison of diet composition between different seasons and years. Seasonal variation in diet composition has been found for G. ogac in Canadian waters (Morin et al., 1991; 1992; Mikhail and Welch, 1989). Furthermore, factors such as diurnal variation in diet (and daily ration) and change in diet associated with energitics of sexual maturation and spawning, as well as changes in average consumption (gastric evacuation rates) per length group could be important for G. ogac feeding ecology as reported for G. morhua by e.g. Köster and Schober (MS 1990) in Greenland waters, and by Magnusson and Palsson (1989) and Stefansson and Palsson (MS 1993, 1997) in Icelandic waters. These factors still remain to be investigated in future studies for G. ogac, however, significant variation in feeding according to these factors is expected in relation to the results obtained from the investigations of feeding ecology of G. morhua in other areas.

\section{Acknowledgements}

This study has been implemented and funded by the former Greenland Fisheries Research Institute, Denmark, (now: Greenland Institute of Natural Resources, Department of Fisheries Biology, P. O. Box 570 DK-3900 Nuuk, Greenland). The stomach sampling program on cod during 1987-89 were carried out as collaboration between this institute and the University of Kiel, Institut für Meereskunde (IfM), Germany. Further, the stomach contents of Gadus morhua were analyzed by IfM, Kiel. We thank Dr. Frank F. Riget, National Environmental Research Institute, Department of Arctic Environment, Denmark, and two anonymous reviewers as well as Associate Editor Dr. D.B. Atkinson, Department of Fisheries and Oceans Science, Canada, and Assistant Executive Secretary (NAFO) Tissa Amaratunga, for helpful comments on the manuscript. Also we thank Dr. Jesper Boje, Greenland Institute of Natural Resources, for help with design of the geographical maps of the survey areas.

\section{References}

ANDERSEN, M. MS 1991. Uvakkens udbredelse og fødebiologi i relation til torsken. M.Sc. Thesis, Marine Biological Institute, University of Copenhagen, 86 pp. +7 pp. (In Danish).

ANDERSEN, O. G. .N, J. R. NIELSEN, and E. L. B. SMIDT.
1994. Description and comparison of eggs and yolk sac larvae of Greenland cod (Gadus ogac), Atlantic cod (Gadus morhua) and Arctic cod (Boreogadus saida) from West Greenland waters. J. Northw. Atl. Fish. Sci., 16: 19-32.

BROMLEY, P. J., and J. M. LAST. MS 1990. Feeding in the trawl and the consequences for estimating food consumption in natural fish populations. ICESC. M. Doc., No. G:35, 10 p.

BUCH, E., S. A. HORSTED, and H. HOVGÅRD. 1994. Fluctuations in the occurrence of cod in Greenland waters and their possible causes. ICES Mar. Sci. Symp., 198: $158-174$.

CHAPUT, G. J. MS 1981. The feeding of Atlantic cod (Gadus morhua) and Rock Cod (Gadus ogac) from inshore Labrador summer 1980. OLABS (Offshore Labrador Biological Studies) PROGRAM REPORT to Petro-Canada Explorations Ltd. by LGL Ltd., St. John's, Newfoundland, Canada, $107 \mathrm{p}$.

HANSEN, P. M. 1949. Studies on the biology of the cod in Greenland waters. ICES Rapp. Proc-Verb., 123: 1-83.

HOVGÅRD, H., and F. F. RIGET. MS 1990. A long-line estimate of swept area abundance of cod in inshore areas off West Greenland. Working paper presented to ICES WG of Fishing Technology and Fish Behaviour, Rostock, Germany, April 1990, 15 p.

1992. Comparison of longline and trawl selectivity in cod surveys off West Greenland. Fish. Res., 13: 323-333.

HØPNER PETERSEN, G., and E. SMIDT. 1981. Havbundens invertebratfauna. In: Danmarks Natur, 11: 241-252. (In Danish).

ICES. 2000. Report of the ICES Advisory Committee on Fishery Management, 1999. ICES Coop. Res. Rep., 236: 90-102.

JENSEN, A. S. 1909a. Beretninger vedr. Grønland 1909 (1). Rapport til Indenrigsministeriet over Briggen "Tjalfe"s praktisk-videnskabelige fiskeriekspedition til Grønland. Indberetning om Fiskeriundersøgelserne ved Grønland i 1908. Beretn. Kundg. Kolonierne Grønl., 2: 11-23. (In Danish).

1909b. Beretninger vedr. Grønland 1909 (2). Rapport til Indenrigsministeriet over Briggen "Tjalfe"s praktiskvidenskabelige fiskeriekspedition til Grønland. Beretning om fiskeriundersøgelserne ved Grønland. Beretn. Kundg. Kolonierne Grønl., 5: 73-106. (In Danish).

1948. Contributions to the Ichtyofauna of Greenland 9 (8-24). Bianco Lunos Bogtrykkeri A/S, Copenhagen, Denmark, $182 \mathrm{p}$.

KÖSTER, F., and W. SCHOBER. MS 1990. Cod stomach sampling in West-Greenland waters 1989 - some preliminary results. NAFO SCR. Doc., No. 33, Serial No. N1750, 13 p.

LILLY, G. R. 1994. Predation by Atlantic cod on capelin on the southern Labrador and Northeast Newfoundland shelves during a period of changing spatial distributions. ICES Mar. Sci. Sym., 198: 600-611.

LILLY, G. R., and J. C. RICE. MS 1983. Food of Atlantic cod (Gadus morhua) on the northern Grand Bank in spring. 
NAFO SCR. Doc., No. 87, Serial No. N753, 35 p.

MAGNUSSON, K. G., and O. K. PALSSON. 1989. Trophic ecological relationships of Icelandic cod. ICES Rapp. Proc-Verb., 188: 206-224.

MIKHAIL, M. Y., and H. E. WELCH. 1989. Biology of Greenland cod, Gadus ogac, at Saqvaqjuac, northwest coast of Hudson Bay. Env. Biol. Fish., 26: 49-62.

MORIN, R., and J. J. DODSON. 1986. The ecology of fishes in James Bay, Hudson Bay and Hudson Strait. In: Canadian Inland Seas, Elsevier, New York. I. P. Martini (ed.). Elsevier Oceanog. Ser., 44, 293-325.

MORIN, B., C. HUDON, and F. G. WHORISKEY. 1991. Seasonal distribution, abundance, and life history traits of Greenland cod, Gadus ogac, at Wemindji, eastern James Bay. Can. J. Zool., 69: 3061-3070.

MORIN, B., C. HUDON, and F. G. WHORISKEY. 1992. Environmental influences on seasonal distribution of coastal and estuarine fish assemblages at Wemindji, eastern James Bay. Env. Biol. Fish., 35: 219-229.

MUUS, B., F. SALOMONSEN, and C. VIBE. 1981. Grønlands Fauna: fisk, fugle, pattedyr. (Fauna of Greenland: fish, birds, mammals). Gyldendal, Copenhagen. ISBN a87-0177101-9. 463 p. (In Danish).

NIELSEN, J. R. MS 1992a. Uvakkens Biologi Gadus ogac (Richardson). (The biology of Greenland cod, Gadus ogac (Richardson)). Report to the Home Rule, Greenland. Greenland Fisheries Research Institute, Copenhagen. ISBN 87-87838-93-1, 119 p. +5 p. (In Danish; summary in Greenlandic).

MS 1992b. Growth of Greenland cod, Gadus ogac, in the Nuuk area of West Greenland. ICES C. M. Doc., No. G:32, 28 p.

NIELSEN, J. R., and R. MORIN. 1993. Bibliography of Greenland cod, Gadus ogac Richardson, 1780-1992. Can. Man. Rep. Fish. Aquat. Sci., 2191: III + 28 p.
PALSSON, O. K. 1983. The feeding habits of demersal fish species in Icelandic waters. J. Mar. Res. Inst. Reykjavik, 7(1): $1-60$.

PALSSON, O. K., and H. BJÖRNSSON. MS 1993. Spatial distributions of stomach content data of Icelandic cod. ICES 1993/CCC Symposium/No. 33, 32 p.

PAZ, J., M. CASAS, and G. PEREZ-GANDARAS. MS 1991. The feeding of cod (Gadus morhua) on Flemish Cap 198990. NAFO SCR Doc., No. 31, Serial No. N1911, 19 p.

RICHARDSON, J. 1836. The Fish. In: Fauna BorealiAmericana; or the zoology of the northern parts of British America containing descriptions of the objects of natural history collected on the late northern land expeditions under the command of Sir J. Franklin R. N., 3(1-15): 1-327.

SAS INSTITUTE INC. 1990. SAS/STAT User's Guide, Version 6, Fourth Edition, Volume 1\&2. SAS Institute Inc., Cary, NC, USA. ISBN 1-55544-376-1. 846 p.

1991a. SAS Language and Procedures: Usage 2, Version 6, First Edition. SAS Institute Inc., Cary, NC, USA. ISBN 1-55544-445-8. 649 p.

1991b. SAS System for Linear Models. Third edition. SAS Series in Statistical Applications. SAS Institute Inc., Cary, NC, USA. ISBN 1-55544-430-X. $329 \mathrm{p}$.

STEFANSSON, G., and O. K. PALSSON. MS 1993. Stastical analyses of stomach content data. ICES 1993 CCC/No. 46, Symposium on Cod and Climate Change, Reykjavik, Iceland, August 1993, $30 \mathrm{p}$.

1997. Statistical evaluation and modeling of the stomach contents of Icelandic cod (Gadus morhua). Can. J. Fish. Aquat. Sci., 54: 169-181.

TIEDTKE, J. E. 1988. Qualitative and quantitative untersuchungen des mageninhaltes vom Kabeljau ( $G$. morhua L.) aus Westgrönlandischen gewassern. Mitt. Inst. Seefisch., 43, 106 p. 
APPENDIX TABLE 1. Number of hooks set and number of longline settings (in brackets) by year, NAFO Division and area (Offshore, Coastal and Inshore), and depth stratum during the 1987-89 longline surveys. Total number of longline sets was 339 corresponding to ca. 136000 hooks set in total, with an average of 400 hooks per longline set.

\begin{tabular}{|c|c|c|c|c|c|c|c|c|c|c|c|c|c|c|}
\hline $\begin{array}{l}\text { NAFO } \\
\text { Division }\end{array}$ & $\begin{array}{l}\text { Depth } \\
\text { stratum } \\
(\mathrm{m})\end{array}$ & Offsho & & $\begin{array}{r}198 \\
\text { Coas }\end{array}$ & & Insho & & Offsh & & $\begin{array}{c}\text { Year } \\
1988 \\
\text { Coastal }\end{array}$ & Insho & & Coastal & $\begin{array}{c}1989 \\
\text { Inshore }\end{array}$ \\
\hline \multirow{4}{*}{ 1B } & $0-100$ & & $\ldots$ & & $\ldots$ & & $\ldots$ & & $\ldots$ & $\ldots$ & & $\ldots$ & $3600 \quad(9)$ & 2400 \\
\hline & $101-200$ & & $\ldots$ & & $\ldots$ & & $\ldots$ & & $\ldots$ & $\ldots$ & & $\ldots$ & $3600 \quad(9)$ & 2400 \\
\hline & $201-300$ & & $\ldots$ & & $\ldots$ & & $\ldots$ & & $\ldots$ & $\ldots$ & & $\ldots$ & $800 \quad(2)$ & 1200 \\
\hline & $0-100$ & 1200 & (3) & 2800 & (7) & 800 & (2) & 1600 & (4) & $4000(10)$ & 1200 & (3) & $2000 \quad(5)$ & 3200 \\
\hline \multirow[t]{3}{*}{$1 \mathrm{C}$} & $101-200$ & 2800 & (7) & 2800 & (7) & 800 & (2) & 2000 & (5) & $2800 \quad(7)$ & 1200 & (3) & $2400 \quad(6)$ & 1600 \\
\hline & $201-300$ & 1200 & (3) & 800 & (1) & & $\ldots$ & 400 & (1) & $1200 \quad(3)$ & 800 & (2) & $800 \quad(2)$ & 800 \\
\hline & $0-100$ & 4800 & 12) & 3600 & (9) & 2000 & (5) & 2800 & (7) & $4000(10)$ & 800 & (2) & $6800(17)$ & 2400 \\
\hline \multirow[t]{3}{*}{$1 \mathrm{D}$} & $101-200$ & 2400 & (6) & 1600 & (4) & 1200 & (3) & 3200 & (8) & $4400(11)$ & 1600 & (4) & 3200 & 1200 \\
\hline & $201-300$ & 2000 & (5) & 1600 & (4) & 2400 & (6) & 1600 & (4) & $1200 \quad(3)$ & 800 & (2) & $1200 \quad(3)$ & 900 \\
\hline & $0-100$ & 400 & (1) & 2800 & (7) & 800 & (2) & 400 & (1) & 400 & 400 & (1) & $2400 \quad(6)$ & 800 \\
\hline \multirow[t]{2}{*}{$1 \mathrm{E}$} & $101-200$ & 2800 & (7) & 2800 & (7) & 800 & (2) & & $\cdots$ & 800 & 400 & (1) & 1200 & 1200 \\
\hline & $201-300$ & 800 & (2) & 400 & (1) & 800 & (2) & 800 & (2) & 400 & & $\ldots$ & $1200 \quad(3)$ & 1200 \\
\hline
\end{tabular}

... No observations.

APPENDIX TABLE 2. Identified taxonomic prey groups for Gadus ogac and Gadus morhua during the autumn period at West Greenland. The prey groups were sorted to lowest taxonomic level possible taking the degree of digestion into account.

\begin{tabular}{|c|c|c|c|}
\hline Number & Taxonomic prey group & Number & Taxonomic prey group \\
\hline 1 & Pisces & 28 & Pontophilus norvegicus \\
\hline 2 & Mallotus villosus & 29 & Hippolytidae \\
\hline 3 & Pholis sp. & 30 & Ealus sp. \\
\hline 4 & Leptoclinus maculatus & 31 & Ealus fabricii \\
\hline 5 & Aspidophoroides monopterygius & 32 & Lebbeussp. \\
\hline 6 & Cottidae & 33 & Lebbeus polaris \\
\hline 7 & Artediellus sp. & 34 & Lebbeus groenlandicus \\
\hline 8 & Myoxocephalus sp. & 35 & Spirontocaris spinus \\
\hline 9 & Triglops sp. & 36 & Spirontocaris lilljeborgi \\
\hline 10 & Reinhardtius hippoglossoides & 37 & Pandalus sp. \\
\hline 11 & Crustacea & 38 & Pandalus montagui \\
\hline 12 & Hyperiidae & 39 & Pandalus borealis \\
\hline 13 & Hyperia sp. & 40 & Brachyura \\
\hline 14 & Parathemisto sp. & 41 & Hyas sp. \\
\hline 15 & Gammaridea & 42 & Hyas coarctatus \\
\hline 16 & Anonyx nugax & 43 & Hyas araneus \\
\hline 17 & Rhachotropsis sp. & 44 & Holothuroidea \\
\hline 18 & Neopleustes sp. & 45 & Echinoidea \\
\hline 19 & Gammarus sp. & 46 & Ophiuroidea \\
\hline 20 & Gammarellus sp. & 47 & Gastropoda \\
\hline 21 & Caprellidea & 48 & Bivalvia \\
\hline 22 & Euphausiacea & 49 & Cephalopoda \\
\hline 23 & Thysanoessa sp. & 50 & Polychaeta (Errantia/Sedentaria) \\
\hline 24 & Natantia & 51 & Hydrozoa \\
\hline 25 & Crangonidae & 52 & Bryozoa \\
\hline 26 & Schlerocrangon ferox & 53 & Algae \\
\hline 27 & Schlerocrangon boreas & & \\
\hline
\end{tabular}


APPENDIX TABLE 3. Description of Degrees of Digestion (DoD) of fish from Bromley and Last (1990).

\begin{tabular}{lcl}
\hline \hline Prey group & DoD & \multicolumn{1}{c}{ Description of Degree of Digestion } \\
\hline Fish & 1 & Intact, no obvious digestion \\
& 2 & Signs of initial digestion, abrasion of skin, fins eroded \\
& Body wall eroded through to visceral cavity, fins eroded, \\
& skin most/all gone but the fish can still be measured \\
& from head to base of tail \\
& Heavily digested, head/tail missing, cannot be measured \\
& Broken flesh and bones - about 50:50 \\
& 5 & Just bones \\
\hline
\end{tabular}

